January, 2008

\title{
Gains from Manipulating Social Choice Rules
}

\section{Donald E. Campbell ${ }^{1}$ and Jerry S. Kelly ${ }^{2}$}

1 Department of Economics and The Program in Public Policy, The College of William and Mary, Williamsburg, VA 23187-8795

(e-mail: $\underline{\text { decamp@,wm.edu) }}$

2 Department of Economics, Syracuse University, Syracuse, NY 13244-1020

(e-mail: jskelly@maxwell.syr.edu)

$$
\text { Page -1- }
$$




\begin{abstract}
Gibbard-Satterthwaite analysis is extended by examining the size of the potential gains that can be achieved from manipulation.
\end{abstract}

Page -2- 


\section{Gains from Manipulating Social Choice Rules \\ Donald E. Campbell and Jerry S. Kelly ${ }^{1}$}

\section{Section 1. Introduction.}

Section 2. Definitions and first examples.

Section 3. General remarks.

Section 4. Rules with $\rho(f)=m$ but small gain.

Section 5. Condorcet.

Section 6. Scoring rules.

Subsection 6.1. Standard rules with two values.

Subsection 6.2. Standard rules with three values.

Subsection 6.3. Standard rules with $\mathrm{m}$ values.

Section 7. Tops-only and vector rules.

Section 8. Final remarks.

\section{Section 1. Introduction.}

The Gibbard-Satterthwaite theorem [Gibbard (1973), Satterthwaite (1975)] is a standard point of entry to the study of implementation theory and mechanism design [e.g., Sonnenschein (1998), Mas-Colell, Whinston and Green (1995)] and is a core topic in social choice theory. The theorem tells us that essentially all rules are manipulable, but does not reveal the potential gains that can be achieved from manipulation or specify consequent losses by others. The present paper extends the Gibbard-Satterthwaite analysis in the study of potential gains while a companion paper [Campbell and Kelly (2007)] treats the losses borne by other individuals when one manipulates for gain.

1 The authors are grateful for an invitation from the University of Athens to visit their PhD program where some of this work was done. 
This paper is part of a large literature on "degree of manipulability." A rule may be thought of as less manipulable if it is manipulable at fewer profiles [Peleg (1979); Nitzan (1985); Chamberlain (1985); Lepelley and Mbih (1987); Saari (1990); Kelly (1993); Kim and Roush (1996)].

As a special case, one could seek rules manipulable at a minimum number of profiles [Kelly (1988); Fristrup and Keiding (1998); Maus, Peters, and Storcken (2005a, 2005b, 2005c, 2005d)]. Alternatively, a rule is less manipulable if there is a smaller number of manipulating strategies [Chamberlain (1985); Smith (1999); Aleskerov and Kurbanov (1999)], if more information is required to determine a manipulating strategy [Nurmi (1987)], if the average size of a manipulating coalition must be larger [Chamberlain (1985); Lepelley and Mbih (1994); Pritchard and Slinko (2006)], or if there exist countercoalitions to manipulations [Pattanaik (1976a, 1976b, 1978); Favardin, Lepelley, and Serias (2002)].

Here we explore a different approach: If a rule allows only small gains from manipulation, we may be persuaded that the cost to the individual of gathering enough information about the preferences of others to ensure that manipulation is advantageous will not yield a gain once those costs are factored in. A referee has directed our attention to two papers that have looked at the possibility of allowing small gains from manipulation, Schummer (2004) and Ehlers, Peters, and Storcken (2004). Both of these papers work in a very different context than we consider here. For them, the feasible set is a continuum, $\mathbb{R}^{2}$ for Schummer and $\mathbb{R}^{\mathrm{m}}$ for Ehlers et al. They thus can not measure gains by number of ranks risen and have to introduce very restricted utility functions to measure gains: linear for Schummer and Lipschitz continuous for Ehlers et al. Our analysis assumes a finite number of alternatives, (unrestricted) strong preferences, and 
measures gains by how many ranks one rise up in one's preference ordering. We are generalizing Gibbard and Satterthwaite, which says only gain $\geq 1$, by using only their assumptions (nondictatorship, full domain, and sufficiently large range) while establishing lower bounds on the possible gains from manipulation greater than 1 .

\section{Section 2. Definitions and first examples.}

$\mathrm{X}=\left\{\mathrm{x}_{1}, \mathrm{x}_{2}, \ldots, \mathrm{x}_{\mathrm{m}}\right\}$ is the finite set of $\mathrm{m}$ alternatives. $\mathrm{N}=\{1,2, \ldots, \mathrm{n}\}$ is the finite set of $\mathrm{n}$ individuals. For any subset $\mathrm{Y}$ of $\mathrm{X}$, let $\mathscr{L}(\mathrm{Y})$ represent the set of all strong (transitive and asymmetric) orderings on $\mathrm{Y}$. A profile is a function from $\mathrm{N}$ into $\mathscr{L}(\mathrm{X})$ and $\rho$ denotes the set of all profiles. We let $\mathrm{p}(\mathrm{h})$ denote the ordering assigned to person $\mathrm{h}$ by profile $\mathrm{p}$. Two profiles are $\boldsymbol{h}$ variants, where $h \in N$, if $q(i)=p(i)$ for all $i \neq h$. For strong ordering $p(h)$, we let $p(h)[k]$ denote the alternative in the $k$ th rank of $p(h)$ and we let $p(h)[1: k]$ denote an initial segment of $p(h)$, the set of alternatives in the top $\mathrm{k}$ ranks of $\mathrm{p}(\mathrm{h})$.

A social choice rule $\mathrm{f}$ is a function from $\rho$ into $\mathrm{X}$. Note that a full domain assumption is built in. For a rule $f$ and non-negative integer $t$, we say $f$ allows a gain of $t$ if there exist two profiles $\mathrm{p}$ and $\mathrm{q}$ and an individual $\mathrm{h}$ such that:

(1) p and q are h-variants;

(2) $f(q)$ ranks t positions higher in $p(h)$ than $f(p)$.

A rule $f$ has a gain of $k$, written $G(f)=k$, if $k$ is the maximum $t$ such that $f$ allows a gain of $t$.

$\mathrm{G}(\mathrm{f})$ is bounded above by $\mathrm{m}-1$; with no restrictions on the rule $\mathrm{f}$, the gain $\mathrm{G}(\mathrm{f})$ can be as large as $\mathrm{m}-1$.

Example 2.1. For the rule $f$ that always selects the alternative lowest in individual \#1's ranking, $\mathrm{p}(1)$, it is easy to confirm that $\mathrm{G}(\mathrm{f})=\mathrm{m}-1$. 
Just as the Gibbard-Satterthwaite theorem has to distinguish dictatorial from nondictatorial rules, so we will find the gain of a rule to be closely related to the extent to which a rule favors some individual, by which we mean, in this paper, the extent to which some individual can precipitate the chosen alternative to be from some initial segment of their ordering. Two more illustrative examples follow:

Example 2.2. For even $n$, fix $k>1$ and define rule $f$ as follows: For arbitrary $p \in \mathcal{P}$, let $Y_{p}$ $=\{\mathrm{p}(1)[1], \mathrm{p}(1)[\mathrm{k}]\}$. Then $\mathrm{f}(\mathrm{p})$ is the alternative in $\mathrm{Y}_{\mathrm{p}}$ that a majority of the individuals in $\mathrm{N} \backslash\{1\}$ prefer to the other member of $Y_{p}$.

Consider profiles p:

\begin{tabular}{|c|c|}
\hline 1 & $\mathrm{i}>1$ \\
\hline $\mathrm{x}_{1}$ & $\mathrm{x}_{\mathrm{k}}$ \\
$\mathrm{x}_{2}$ & $\mathrm{x}_{1}$ \\
$\vdots$ & $\mathrm{x}_{2}$ \\
$\mathrm{X}_{\mathrm{k}}$ & $\vdots$ \\
$\vdots$
\end{tabular}

and q:

\begin{tabular}{|c|c|}
\hline 1 & $\mathrm{i}>1$ \\
\hline $\mathrm{x}_{1}$ & $\mathrm{x}_{\mathrm{k}}$ \\
$\mathrm{x}_{\mathrm{k}}$ & $\mathrm{x}_{1}$ \\
$\vdots$ & $\mathrm{x}_{2}$ \\
$\mathrm{x}_{2}$ & \\
$\vdots$ & \\
\hline
\end{tabular}

where $q$ differs from $p$ only in that $x_{2}$ and $x_{k}$ switch places in $p(1)$ to create $q(1)$. Then $f(p)=x_{k}$ while $f(q)=x_{1}$. Therefore, $G(f) \geq k-1$. But $G(f) \leq k-1$ since no $i>1$ finds it beneficial to misrepresent since those individuals are simply choosing from a two-element set by majority rule, 
and so we have $G(f)=k-1$. In summary, $f(p)$ is forced to be in $p(1)[1: k]$ and $G(f)=k-1$.

Example 2.3. $X=\{w, x, y, z\}$ and $n=3$. At any profile $u$, at least one alternative is not anyone's last. Take $\mathrm{f}(\mathrm{u})$ to be the alphabetically ${ }^{2}$ earliest alternative that no one ranks last ${ }^{3}$. Then $\mathrm{f}(\mathrm{u})$ can not be $\mathrm{u}(\mathrm{j})[4]$ for anyone; so no one can gain more than two ranks. The largest gain an individual can realize is to go from $3^{\text {rd }}$ to $1^{\text {st; }}$, for this rule, $G(f)=2$.

\section{Section 3. General remarks.}

The examples of the previous section suggest relating gain to the extent to which individuals can precipitate the chosen alternative to be from initial segments of their ordering. For a rule $f$, let $\rho_{i}(f)$ be the smallest integer s such that for all $p \in \rho, f(p)$ must be in $p(i)[1: s]$, the initial segment of $\mathrm{p}(\mathrm{i})$. A manipulation by $\mathrm{i}$ can gain at most $\rho_{\mathrm{i}}(\mathrm{f})-1$ ranks. Since the individual who manipulates may be an individual with small $\rho_{i}(f)$, we set $\rho(f)$ to be the minimum ${ }^{4}$ over all $i \in N$ of the values $\rho_{i}(f)$. We will let $\rho(f)$ be a benchmark against which we compare $G(f)$. For

2 If as here, the alternatives are letters of the alphabet, the "alphabetically earliest" is interpreted in the usual way; when $X=\left\{\mathrm{x}_{1}, \mathrm{x}_{2}, \ldots, \mathrm{x}_{\mathrm{m}}\right\}$ then the "alphabetical" ordering is $\mathrm{x}_{1}<\mathrm{x}_{2}<\ldots<\mathrm{x}_{\mathrm{m}}$.

3 Example 2.3 is a special case of inverse plurality, axiomatized by Baharad and Nitzan (2005).

${ }^{4}$ For all but a few cases with small $\mathrm{n}$, like Example 2.3, most individuals i will have $\rho_{\mathrm{i}}(\mathrm{f})=$ $\mathrm{m}$. For suppose $\min \rho_{\mathrm{i}}(\mathrm{f})=\mathrm{k}<\mathrm{m}$ and, without loss of generality, let $\rho_{1}(\mathrm{f})=\mathrm{k}$. Then

$$
\sum_{i>1}\left(m-\rho_{t}(f)\right)<k
$$

For example, imagine $\mathrm{n}=10, \mathrm{~m}=5, \rho_{1}(\mathrm{f})=3$. If $\rho_{\mathrm{i}}(\mathrm{f})<\mathrm{m}$ for as many as three individuals $\mathrm{i}>1$, look at a profile $\mathrm{p}$ where $\mathrm{p}(1)[1: 3]=\{\mathrm{x}, \mathrm{y}, \mathrm{z}\}$, but each of these alternatives is at the bottom of someone else's ordering; an inconsistency. Hence at least seven individuals have $\rho_{\mathrm{i}}(\mathrm{f})=\mathrm{m}$. 
almost all rules, $G(f) \geq \rho(f)-2$, but we will see several kinds of rules where $G(f)$ is about half of $\rho(f)$.

Our analysis begins by dividing into three cases based on the size of $\rho(f)$ :

Case 1. $\rho(f)=1$. This case is easily disposed of: someone is a dictator and hence $G(f)=0(=\rho(f)-1)$.

Case 2. $1<\rho(\mathrm{f})<\mathrm{m}$. For this case all our examples will be seen to satisfy the conjecture:

Gain Conjecture \#1: For any rule f with $\mid$ Range(f) $\mid \geq 3$ : if $1<\rho(\mathrm{f})<\mathrm{m}$, then

$$
G(f) \geq \rho(f)-1
$$

A special case of this Conjecture is easy: Suppose that $\rho(f)=2<m$. Since $\rho(f)>1$, $f$ is not dictatorial and the Gibbard-Satterthwaite Theorem tells us $G(f) \geq 1=\rho(f)-1$.

It is possible that $G(f)$ is much larger than $\rho(f)-1$. Because someone other than the individual with smallest $\rho_{\mathrm{i}}(\mathrm{f})$, which determines $\rho(\mathrm{f})$, may be able to manipulate more than that minimum, $\rho(f)-1$.

Example 3.2. For even $n$, fix $k>1$ and define rule f as follows: $f(u)$ is the element within $\mathrm{u}(1)[1: \mathrm{s}]$ that is lowest in $\mathrm{u}(2) . \rho_{1}(\mathrm{f})=\mathrm{s}$ while $\rho_{\mathrm{i}}(\mathrm{f})=\mathrm{m}$ for all $\mathrm{i}>1 . \mathrm{G}(\mathrm{f})=\mathrm{m}-1$ as individual \#2 can manipulate from his last to his first.

Case 3. $\rho(f)=m$. This last case is more complicated. $G(f)$ is either $m-1$ or $m-2$ for almost all rules with $\rho(f)=m$. But we will nevertheless see cases where $G(f)$ can be as small as $\mathrm{m} / 2-1$. 
Section 4. Rules with $\rho(f)=m$ but small gain.

We illustrate the possibility of small gain with three examples. The first has a range that is a proper subset of $\mathrm{X}$.

Example 4.1. $\mathrm{X}=\left\{\mathrm{x}_{1}, \mathrm{x}_{2}, \ldots, \mathrm{x}_{\mathrm{m}}\right\}$ and let $\mathrm{k}$ be an integer between 1 and $\mathrm{m}-1$ inclusive. Let $f(p)$ be the alphabetically earliest alternative $x_{j} \in X$ such that $x_{j}$ is one of the top $k$ alternatives in the ordering $p(i)$, for some individual $i$. This is an anonymous rule for which $\rho(f)=m$. (For example, if $\mathrm{x}_{1}$ is at the bottom of $\mathrm{p}(1)$ and at the top of $\mathrm{p}(2)$ then $\mathrm{f}(\mathrm{p})=\mathrm{x}_{1}$.) However, we will see that, depending on the size of $\mathrm{k}, \mathrm{G}(\mathrm{f})$ can be significantly less than $\mathrm{m}-1$. Consider profile $\mathrm{p}$ :

\begin{tabular}{|c|c|}
\hline 1 & $\mathrm{i}>1$ \\
\hline $\mathrm{X}_{\mathrm{m}-\mathrm{k}+1}$ & $\mathrm{x}_{2}$ \\
\hline $\mathrm{X}_{\mathrm{m}-\mathrm{k}+2}$ & \\
\hline$\vdots$ & $\vdots$ \\
\hline $\mathrm{X}_{\mathrm{m}-1}$ & \\
\hline $\mathrm{X}_{\mathrm{m}}$ & \\
\hline $\mathrm{x}_{1}$ & \\
\hline $\mathrm{x}_{3}$ & $\vdots$ \\
\hline $\mathrm{X}_{4}$ & \\
\hline$\vdots$ & \\
\hline $\mathrm{X}_{\mathrm{m}-\mathrm{k}}$ & \\
\hline $\mathrm{x}_{2}$ & $\mathrm{x}_{1}$ \\
\hline
\end{tabular}

Then $\mathrm{f}(\mathrm{p})=\mathrm{x}_{2}$ but person 1 can get $\mathrm{x}_{1}$, which ranks in position $\mathrm{k}+1$ in $\mathrm{p}(1)$, by reporting an ordering with $\mathrm{x}_{1}$ on top. Therefore, $\mathrm{G}(\mathrm{f}) \geq \mathrm{m}-\mathrm{k}-1$. We can also see that $\mathrm{G}(\mathrm{f}) \geq \mathrm{k}-1$ by considering profile $\mathrm{q}$ for which $\mathrm{q}(1)[\mathrm{k}]=\mathrm{x}_{1}$ : 


$\left.\begin{array}{|c|c|}\hline 1 & \mathrm{i}>1 \\ \hline \mathrm{x}_{2} & \mathrm{x}_{2} \\ \vdots & \vdots \\ \mathrm{x}_{1} & \\ \hline \mathrm{x}_{3} & \\ \vdots & \vdots \\ & \mathrm{x}_{1}\end{array}\right\} \mathrm{k}$

Here, $\mathrm{f}(\mathrm{q})=\mathrm{x}_{1}$; but if individual \#1 interchanges $\mathrm{x}_{1}$ and $\mathrm{x}_{3}$, the outcome will be $\mathrm{x}_{2}$ and \#1 will have gained $k-1$ ranks. In fact, for this $f, G(f)=\operatorname{Max}[m-k-1, k-1]$. To see that, it suffices to observe that no individual has the ability to change the outcome of the rule from one of his bottom $\mathrm{m}-\mathrm{k}$ to one of his top $\mathrm{k}$.

Note that there are $\mathrm{k}-1$ alternatives that are never selected by f. For arbitrary profile $\mathrm{p}$, the top $\mathrm{k}$ alternatives in $\mathrm{p}(1)$ must include at least one alternative $\mathrm{x}_{\mathrm{j}}$ such that $\mathrm{j}<\mathrm{m}-\mathrm{k}+2$, because $\{\mathrm{m}-\mathrm{k}+2, \mathrm{~m}-\mathrm{k}+3, \ldots \mathrm{m}-1, \mathrm{~m}\}$ is a set with only $\mathrm{k}-1$ members. Hence, none of the alternatives $\mathrm{x}_{\mathrm{m}-\mathrm{k}+2}, \mathrm{x}_{\mathrm{m}-\mathrm{k}+3}, \ldots \mathrm{x}_{\mathrm{m}-1}, \mathrm{x}_{\mathrm{m}}$ belongs to the range of $\mathrm{f}$.

Since either $\mathrm{m}-\mathrm{k}$ or $\mathrm{k}$ is at least $\mathrm{m} / 2$, this example is consistent with the following conjecture:

Gain Conjecture \#2: For any rule f with $|\operatorname{Range}(\mathrm{f})| \geq 3$ : if $\rho(f)=m$, then $G(f) \geq m / 2-1$.

Example 4.2. Suppose that $\mathrm{n} \geq 3$. Let $\mathrm{t}_{1}$ and $\mathrm{t}_{2}$ be positive integers such that $\mathrm{t}_{1}+\mathrm{t}_{2}=$ m. At profile $u$, for each individual $i$, assign 0 to the $t_{1}$ alternatives ranked highest in $u(i)$ and 1 to

\section{Section 6.}

${ }^{5}$ This example is a special case of a standard scoring rule. Scoring rules are treated in

$$
\text { Page -10- }
$$


the $t_{2}$ alternatives ranked lowest. Then each alternative $\mathrm{x}$ in $\mathrm{X}$ is assigned the sum of its scores over all $n$ of the $u(i)$ orderings. $f(u)$ is then the alternative with the smallest sum. Of course, ties are possible, so a complete description of f requires a tie-break rule. Here we assume that $\mathrm{X}$ is ordered ("alphabetically") and then $\mathrm{f}(\mathrm{u})$ is the alphabetically earliest of the alternatives with the smallest sum.

Consider now cases where $\mathrm{nt}_{2} \geq \mathrm{m}$. Then a profile $\mathrm{u}$ can be constructed in which every alternative is assigned 1 by at least one individual. Let $\mathrm{i}$ be an individual for whom $\mathrm{f}(\mathrm{u}) \notin$ $p(i)\left[1: t_{1}\right]$. Construct new profile $u^{*}$ by bringing $f(u)$ to i's bottom and having $u$ otherwise unchanged. $f\left(u^{*}\right)=f(u)=u^{*}(i)[m]$. By anonymity, $\rho(f)=m$.

If one of individual $\mathrm{j}$ 's bottom $\mathrm{t}_{2}$ alternatives is selected under truthful revelation, then $\mathrm{j}$ can not precipitate the selection of one of his top $t_{1}$ alternatives by misrepresentation because there is nothing $\mathrm{j}$ can do unilaterally to reduce the score of one of those $\mathrm{t}_{1}$ alternatives. So the possible gains are bounded by the larger of $t_{1}-1$ or $t_{2}-1$. We show $G(f)=\operatorname{Max}\left[t_{1}-1, t_{2}-1\right]$.

To show a gain of $t_{1}-1$ is possible, consider profile $u$ :

$\left.\begin{array}{|c|c|c|c|}\hline 1 & 2 & \cdots & \mathrm{n} \\ \hline \mathrm{b} & \mathrm{b} & \mathrm{b} & \mathrm{b} \\ \mathrm{x} & \mathrm{x} & \mathrm{x} & \mathrm{x} \\ \vdots & \vdots & \vdots & \vdots \\ \mathrm{a} & \mathrm{a} & \mathrm{a} & \mathrm{a} \\ \hline \mathrm{z} & \mathrm{z} & \mathrm{z} & \mathrm{z} \\ \vdots & \vdots & \vdots & \vdots \\ \mathrm{y}\end{array}\right\} \mathrm{t}_{1}$

where $\mathrm{a}$ is in everyone's rank $\mathrm{t}_{1}$. Then $\mathrm{f}(\mathrm{u})=\mathrm{a}$. But if $\mathrm{u}^{*}$ is created by having \#1 interchange a and $\mathrm{z}, \mathrm{f}\left(\mathrm{u}^{*}\right)=\mathrm{b}$ and $\# 1$ gains $\mathrm{t}_{1}-1$ positions.

So we turn our attention to the case where $t_{2}-1>t_{1}-1$. We construct a profile $u$ as Page -11- 
follows:

$\left.\begin{array}{|c|c|c|c|}\hline 1 & 2 & \cdots & \mathrm{n} \\ \hline \mathrm{z} & \mathrm{a} & \mathrm{a} & \mathrm{a} \\ \vdots & \mathrm{b} & \mathrm{b} & \mathrm{b} \\ \vdots & \vdots & \vdots & \vdots \\ \mathrm{p} & \mathrm{k} & \mathrm{k} & \mathrm{k} \\ \mathrm{b} & 1 & 1 & 1 \\ \vdots & \vdots & \vdots & \vdots \\ \mathrm{c} & \vdots & \vdots & \vdots \\ \mathrm{a} & \mathrm{z} & \mathrm{z} & \mathrm{z} \\ \hline\end{array}\right\} \mathrm{t}_{1}$

where

- Individuals $2, \ldots, \mathrm{n}$ all have the same ordering: $\mathrm{ab} \ldots \mathrm{k} 1 \ldots \mathrm{z}$ where $\mathrm{k}$ appears in position $\mathrm{t}_{1}$

- Individual \#1's preferences are a modification of the reverse order $\mathrm{z} \ldots \mathrm{lk} \ldots$ ba. The modification raise $b$ to rank $t_{1}+1$.

Since $t_{2}>t_{1}$, alternatives $a, b, \ldots, k$ are assigned 1 by individual \#1, and those alternatives get a score of just 1 while the score of the other alternatives is at least $n-1 \geq 1$. By the tie-break, $\mathrm{f}(\mathrm{u})=\mathrm{a}=\mathrm{u}(1)[\mathrm{m}]$. If $\mathrm{u}^{*}$ is obtained from $\mathrm{u}$ by interchanging $\mathrm{p}$ and $\mathrm{b}$ for individual 1 , then the score of $b$ decreases to 0 and $f\left(u^{*}\right)=b$, a gain of $t_{2}-1$ ranks.

The same results could all be achieved if instead of an alphabetic tie-break we had used, say, individual \#2's ranking as the tie-break.

Again, $G(f)=\operatorname{Max}\left[t_{1}-1, t_{2}-1\right]$ is consistent with Gain Conjecture \#2.

Example 4.3. $m=100$ and $n=3$. Start with a Rawlsian rule: At profile $u$, for each Page -12- 
alternative $\mathrm{x}$, determine $\mathrm{t}(\mathrm{x})=\max _{\mathrm{i}}\{\mathrm{k}: \mathrm{u}(\mathrm{i})[\mathrm{k}]=\mathrm{x}\}$, the lowest rank occupied by $\mathrm{x}$ over the $\mathrm{n}$ individuals. Then $\mathrm{f}(\mathrm{u})$ is the alphabetically earliest alternative $\mathrm{x}$ with minimum $\mathrm{t}(\mathrm{x})$. For $\mathrm{m}=100$ and $n=3$, the largest possible minimum value of $t(x)$ is 67 and hence $\rho(f)=67$. Gain Conjecture \#1 would lead us to expect that $\mathrm{G}(\mathrm{f}) \geq 66$. Consider profile $\mathrm{u}$ :

$\left.\begin{array}{|c|c|c|}\hline 1 & 2 & 3 \\ \hline \mathrm{x}_{2} & \mathrm{x}_{4} & \mathrm{x}_{5} \\ \vdots & \vdots & \vdots \\ \mathrm{x}_{1} & \mathrm{x}_{2} & \mathrm{x}_{2}\end{array}\right\} 67$

Alternatives $x_{i}$ for $\mathrm{i}>2$ have $\mathrm{t}\left(\mathrm{x}_{\mathrm{i}}\right)>67$, while $\mathrm{t}\left(\mathrm{x}_{1}\right)=\mathrm{t}\left(\mathrm{x}_{2}\right)=67$. By the alphabetic tie-break, $\mathrm{f}(\mathrm{u})=$ $\mathrm{x}_{1}$. If $\mathrm{u}^{*}$ is obtained by having individual \#1 switch $\mathrm{x}_{1}$ and $\mathrm{x}_{3}, \mathrm{t}\left(\mathrm{x}_{2}\right)=67$ is the minimum and $\mathrm{f}\left(\mathrm{u}^{*}\right)$ $=x_{2}$. Thus \#1 gains 66 ranks. Since $\rho(f)=67$, this 66 is the largest possible gain: $G(f)=66$.

Now construct a new rule $\mathrm{g}$, as follows: If at $\mathrm{u}$ there is an alternative $\mathrm{x}$ that is at the top of two or three individual rankings, then $g(u)=x$; otherwise $g(u)=f(u)$. Now $\rho(g)=100$ because one individual's bottom will be selected if it is at the top for the other two. But, $G(g)=66$. To see this, it suffices to see that no one manipulates away from an alternative that is selected when it is at two or more tops. Obviously, $\mathrm{G}(\mathrm{g})=66$ is consistent with Gain Conjecture \#2.

\section{Section 5. Condorcet.}

In this section we compute the gain to manipulation when we impose the condition that $\mathrm{f}$ is a Condorcet rule. Say $\mathrm{x}$ is a strong Condorcet winner if $|\{\mathrm{i}: \mathrm{x} \succ \mathrm{y}\}|>|\{\mathrm{i}: \mathrm{y} \succ \mathrm{x}\}|$ for all $\mathrm{y}$ in 
$\mathrm{X} \backslash\{\mathrm{X}\}$, that is, $\mathrm{x}$ defeats every other alternative under majority voting. Rule $\mathrm{f}$ is a Condorcet rule if for every alternative $x$ and every profile $p$, if $x$ is a strong Condorcet winner at $p$, then $f(p)=x$. Condorcet rules are non-dictatorial, have range $X$, and (if $n>2)$ have $\rho(f)=m$. Note that for $\mathrm{n}=2$, Condorcet does not imply $\rho(\mathrm{f})=\mathrm{m}$; the case $\mathrm{n}=2$ will be taken up later in this section.

Theorem 5.1 (First Condorcet Gain Theorem). If $\mathrm{m} \geq 3$, and $\mathrm{n} \geq 3$ is odd, then $\mathrm{G}(\mathrm{f}) \geq$ $\mathrm{m}-2$ for any Condorcet rule $\mathrm{f}$.

Proof: Suppose that $\mathrm{X}=\{\mathrm{x}, \mathrm{y}, \mathrm{z}, \mathrm{w}, \ldots\}$.

Part 1. Assume first that $\mathrm{n}=3$. Let $\mathrm{p}$ be any profile with the three alternatives $\mathrm{x}, \mathrm{y}$, and $\mathrm{z}$ arranged at the top in a Latin square, thus:

\begin{tabular}{|c|c|c|}
\hline 1 & 2 & 3 \\
$\mathrm{x}$ & $\mathrm{y}$ & $\mathrm{z}$ \\
$\mathrm{y}$ & $\mathrm{z}$ & $\mathrm{x}$ \\
$\mathrm{z}$ & $\mathrm{x}$ & $\mathrm{y}$ \\
$\vdots$ & $\vdots$ & $\vdots$ \\
\hline
\end{tabular}

If $f(p)=x$ then let $p^{\prime}$ be any profile for which $p^{\prime}(2)=p(2)$ and $p^{\prime}(3)=p(3)$, with $x$ ranked 
first in $\mathrm{p}^{\prime}(1), \mathrm{y}$ ranked last in $\mathrm{p}^{\prime}(1)$, and $\mathrm{z}$ second last in $\mathrm{p}^{\prime}(1)$ :

\begin{tabular}{|c|c|c|}
\hline 1 & 2 & 3 \\
$\mathrm{x}$ & $\mathrm{y}$ & $\mathrm{z}$ \\
$\vdots$ & $\mathrm{z}$ & $\mathrm{x}$ \\
$\mathrm{z}$ & $\mathrm{x}$ & $\mathrm{y}$ \\
$\mathrm{y}$ & $\vdots$ & $\vdots$ \\
\hline
\end{tabular}

Notice that at $\mathrm{p}\left(\right.$ and $\mathrm{p}^{\prime}$ ) both persons 2 and 3 prefer $\mathrm{z}$ to every other alternative except $\mathrm{y}$, and that at $\mathrm{p}^{\prime}$ both persons 1 and 3 prefer $\mathrm{z}$ to $\mathrm{y}$. Therefore, $\mathrm{z}$ is a Condorcet winner at $\mathrm{p}^{\prime}$, and hence $\mathrm{f}\left(\mathrm{p}^{\prime}\right)$ $=\mathrm{z}$. But $\mathrm{z}$ ranks second last in $\mathrm{p}^{\prime}(1), \mathrm{x}$ ranks first, and at profile $\mathrm{p}^{\prime}$ person 1 can precipitate the selection of $x$ by reporting $p(1)$. Therefore, $G(f) \geq m-2$ if $f(p)=x$. By a similar analysis, $G(f) \geq$ $\mathrm{m}-2$ if $\mathrm{f}(\mathrm{p})=\mathrm{y}$ or $\mathrm{f}(\mathrm{p})=\mathrm{z}$

Now suppose that, with $\mathrm{p}$ as given in the table above, $\mathrm{f}(\mathrm{p})=\mathrm{w} \in \mathrm{X} \backslash\{\mathrm{x}, \mathrm{y}, \mathrm{z}\}$. Let $\mathrm{p}^{\prime \prime}$ be the following profile for which $\mathrm{p}^{\prime \prime}(2)=\mathrm{p}(2)$ and $\mathrm{p}^{\prime \prime}(3)=\mathrm{p}(3)$ :

\begin{tabular}{|c|c|c|}
\hline 1 & 2 & 3 \\
$\mathrm{w}$ & $\mathrm{y}$ & $\mathrm{z}$ \\
$\vdots$ & $\mathrm{z}$ & $\mathrm{x}$ \\
$\mathrm{z}$ & $\mathrm{x}$ & $\mathrm{y}$ \\
$\mathrm{y}$ & $\vdots$ & $\vdots$ \\
\hline
\end{tabular}

Page -15- 
Then $\mathrm{z}$ is a strong Condorcet winner at $\mathrm{p}^{\prime \prime}$. Therefore, $\mathrm{f}\left(\mathrm{p}^{\prime \prime}\right)=\mathrm{z}$. But $\mathrm{z}$ ranks second last in $\mathrm{p}^{\prime \prime}(1)$, and at profile $\mathrm{p}^{\prime \prime}$ person 1 can precipitate the selection of her top ranked alternative w by reporting $p(1)$. Therefore, $G(f) \geq m-2$ in this case as well.

Part 2. Assume now that $\mathrm{n}>3$ and $\mathrm{n}$ is odd. Construct $\mathrm{p}$ by letting $\mathrm{p}(1), \mathrm{p}(2)$, and $\mathrm{p}(3)$ be as in Part 1 above. Let $\mathrm{Q}$ be any strong ordering on $\mathrm{X}$ and set $\mathrm{p}(\mathrm{i})=\mathrm{Q}$ for any even $\mathrm{i}>2$. Let $\mathrm{R}$ be the inverse of $\mathrm{Q}$ obtained by turning $\mathrm{Q}$ upside down. Set $\mathrm{p}(\mathrm{i})=\mathrm{R}$ for every odd $\mathrm{i}>3$. Note that we can partition the individuals in $\{4,5, \ldots, \mathrm{n}\}$ so that half have $\mathrm{Q}$ at $\mathrm{p}$ and half have $\mathrm{R}$. Therefore, in determining a strong Condorcet winner (or the absence of one) the individuals $i>3$ can be ignored because they offset each other in terms of the vote count. Then the argument that we employed above for $n=3$ can be applied without modification to establish $G(f) \geq m-2$.

This First Condorcet Theorem allows $\mathrm{G}(\mathrm{f})=\mathrm{m}-1$ or $\mathrm{m}-2$. Both possibilities can be realized.

Example 5.1. Let $\mathrm{f}$ be the rule that selects the Condorcet winner if there is one and otherwise picks individual $\# 1$ 's bottom ranked alternative. It can be shown that $\mathrm{G}(\mathrm{f})=\mathrm{m}-1$ (by manipulations from one non-Condorcet winner to another).

Example 5.2. Let $\mathrm{f}$ be the rule that selects the Condorcet winner if there is one and otherwise picks the alphabetically earliest of the tops. To see that $G(f)=m-2$, suppose that $\alpha$ is at the bottom of $\mathrm{u}(\mathrm{i})$ and is chosen. If $\alpha$ is a Condorcet winner, there is nothing $\mathrm{i}$ can do to prevent $\alpha$ from being a Condorcet winner. If there is no Condorcet winner and $\alpha$ is the alphabetically earliest top, let $\beta$ be the top of $u(i)$, so $\alpha$ precedes $\beta$ alphabetically. Then there is nothing $i$ can do to make $\beta$ a Condorcet winner and i can not alter the fact that $\alpha$ beats $\beta$ alphabetically.

$$
\text { Page -16- }
$$


The First Condorcet Theorem does not extend to $n=2$ even if we add anonymity, as we show by the next example. When $n=2$, Condorcet is very weak and does not even imply $\rho(f)=m$ as it does for all larger $n$. But $\rho(f)=m$ for the next example, which also satisfies a Pareto condition and anonymity. The example has $\mathrm{n}=2, \mathrm{~m}=4$, and $\mathrm{G}(\mathrm{f})=1$, although the rule is Condorcet.

Example 5.3. Let $\mathrm{n}=2$ and $\mathrm{X}=\{\mathrm{x}, \mathrm{y}, \mathrm{z}, \mathrm{w}\}$ with $\mathrm{f}(\mathrm{u})$ determined by a sequence of steps:

Step 1. If at profile $\mathrm{u}$, anyone has $\mathrm{w}$ at her top, $\mathrm{f}(\mathrm{u})=\mathrm{w}$.

Step 2. If at profile $\mathrm{u}$, both individuals have the same alternative $\alpha \in\{\mathrm{x}, \mathrm{y}, \mathrm{z}\}$ at their top, then $\mathrm{f}(\mathrm{u})=\alpha$.

Step 3. If at profile u neither Steps 1 nor 2 apply, consider the following list of orderings: zw; yw; xw; zy; zx; yz; yx.

At least one individual must have one of those orderings as their initial segment. Pick the individual with the initial segment of their order, say $\alpha \beta$, earliest in the list. Then $\mathrm{f}(\mathrm{u})$ is that alternative in $\{\alpha, \beta\}$ that is preferred by the other individual.

First $\rho(f)=4$ as $w$ will be chosen when it is at one person's bottom and at the other's top. It can be shown that only w can be chosen from someone's bottom and that no one ever manipulates to $\mathrm{w}$.

It is clear that this rule satisfies anonymity. We next show it satisfies Pareto and hence is Condorcet. That is, we want to show that if $\mathrm{f}(\mathrm{u})=\alpha$, there is no $\beta$ such that both prefer $\beta$ to $\alpha$. This is obvious if $\mathrm{f}(\mathrm{u})=\alpha$ via Steps 1 or 2. So suppose that $\mathrm{f}(\mathrm{u})=\alpha$ by Step 3. Then one individual has initial segment either $\alpha \beta$ or $\beta \alpha$. Clearly if the initial segment is $\alpha \beta$, there is no alternative both prefer to $\alpha$. But if the initial segment is $\beta \alpha$, the only possible alternative both 
prefer to $\alpha$ is $\beta$. But if the other individual also prefers $\beta$ to $\alpha$, then $\alpha$ wouldn't have been chosen.

Finally we show $G(f)=1$. So suppose that $f(u)=\alpha$; we want to show no one can improve to an outcome two or more ranks higher in their ordering.

1. $\mathrm{f}(\mathrm{u})=\alpha$ arises from Step 1 . An individual with $\mathrm{w}$ on their top can not improve at all, and the other individual can not affect the outcome.

2. $\mathrm{f}(\mathrm{u})=\alpha$ arises from Step 2. Each individual has $\alpha$ as their top and so can not improve at all.

3. $f(u)=\alpha$ arises from Step 3. Some individual has $\alpha \beta$ or $\beta \alpha$ as her initial segment; the other individual's initial segment appears later in the list and that individual prefers $\alpha$ to $\beta$ (and so can't gain three ranks). Now the first individual can not improve two ranks (or three) since $\alpha$ is in their initial segment of length two. The only way the other individual could improve two ranks would be if they had ordering $\gamma \delta \alpha \beta$ and could precipitate the selection of $\gamma$. But since $\gamma \delta$ is later in the list than the first individual's initial segment, the other would have to submit an ordering with one of $\gamma \alpha, \gamma \beta, \alpha \gamma$, or $\beta \gamma$ as initial segment. But then since the first individual prefers each of $\alpha$ and $\beta$ to $\gamma$, alternative $\gamma$ wouldn't be chosen.

The fact that $\mathrm{n}=2$ in Example 4.3 is crucial for obtaining $\mathrm{G}(\mathrm{f})=1$.

Open Question: For $\mathrm{m} \geq 3$ and even $\mathrm{n} \geq 4$, does every Condorcet social choice rule $\mathrm{f}$ satisfy $G(f) \geq m-2$ ?

We next show that if we strengthen the Condorcet condition slightly, the answer is "yes." With even $\mathrm{n}$, the Condorcet condition is weak. We can strengthen it by requiring that if at profile $u$ there exist alternatives that are not defeated by majority vote, then $f(u)$ is one of those

$$
\text { Page -18- }
$$


alternatives. An alternative $\mathrm{x}$ is a Condorcet non-loser if there is no other alternative $\mathrm{y}$ that defeats $\mathrm{x}$ by majority vote (though there may be alternatives that are tied with $\mathrm{x}$ ). Then, because so many ties are possible, rules are heavily influenced by how ties are broken. A selection function, $\mathrm{t}$, chooses an element from each subset Y of X:

$$
\mathrm{t}(\mathrm{Y}) \in \mathrm{Y}
$$

A rule $\mathrm{f}$ is fully Condorcet if there is a selection function $\mathrm{t}$ such that, for each profile $\mathrm{u}$ for which the set $\mathrm{Y}(\mathrm{u})$ of Condorcet non-losers is non-empty, $\mathrm{f}(\mathrm{u})=\mathrm{t}(\mathrm{Y}(\mathrm{u}))$. For even $\mathrm{n}$, the selection function for any fully Condorcet rule is unique. The selection function $t$ need not be "rationalized" - $\mathrm{t}(\mathrm{Y})$ need not be the highest element in some transitive ordering. It is also important to note here that $\mathrm{t}(\mathrm{Y}(\mathrm{u}))$ depends only on $\mathrm{Y}(\mathrm{u})$, and not separately on $\mathrm{u}$ : Hence $\mathrm{Y}(\mathrm{u})=\mathrm{Y}(\mathrm{v}) \neq \varnothing$ implies $\mathrm{f}(\mathrm{u})=\mathrm{f}(\mathrm{v})$. For a fully Condorcet rule, Range(f) $=\mathrm{X}$ and $\rho(\mathrm{f})=\mathrm{m}$, even if $\mathrm{n}=2$. (Proof: If $\mathrm{t}(\mathrm{X})=$ $\mathrm{x}$, let $\mathrm{Q}$ be a strong order with $\mathrm{x}$ at the top. Let $\mathrm{R}$ be the inverse of $\mathrm{Q}$. Then consider a profile $\mathrm{u}$ where half of the individuals are assigned Q and half are assigned R.)

Notice that Example 4.3 is not fully Condorcet as its tie-break can not be represented by a selection function. To see this, look at two profiles; the first is u:

\begin{tabular}{|c|c|}
\hline 1 & 2 \\
& \\
\hline $\mathrm{x}$ & $\mathrm{z}$ \\
$\mathrm{y}$ & $\mathrm{y}$ \\
$\mathrm{z}$ & $\mathrm{x}$ \\
$\mathrm{w}$ & $\mathrm{w}$ \\
\hline
\end{tabular}

The set of Condorcet non-losers is $\{\mathrm{x}, \mathrm{y}, \mathrm{z}\}$. Now $\mathrm{f}(\mathrm{u})=\mathrm{y}$ since $\# 2$ has the ordering with initial segment, zy, earlier in the list than xy and \#1 prefers $\mathrm{y}$ to $\mathrm{z}$. If $\mathrm{f}$ were fully Condorcet via selection Page -19- 
function $\mathrm{t}$, we would need $\mathrm{t}(\{\mathrm{x}, \mathrm{y}, \mathrm{z}\})=\mathrm{y}$. But look at the second profile, $\mathrm{v}$ :

\begin{tabular}{|c|c|}
\hline 1 & 2 \\
\hline $\mathrm{x}$ & $\mathrm{y}$ \\
$\mathrm{z}$ & $\mathrm{z}$ \\
$\mathrm{y}$ & $\mathrm{x}$ \\
$\mathrm{w}$ & $\mathrm{w}$ \\
\hline
\end{tabular}

Again the set of Condorcet non-losers is $\{x, y, z\}$. Since $t(\{x, y, z\})=y$, fully Condorcet would require $\mathrm{f}(\mathrm{v})=\mathrm{y}$. But $\mathrm{f}(\mathrm{v})=\mathrm{z}$ since $\# 2$ has the ordering with initial segment, yz, earlier in the list than $\mathrm{xz}$ and $\# 1$ prefers $\mathrm{z}$ to $\mathrm{y}$.

Theorem 5.2 (Second Condorcet Gain Theorem). For even $\mathrm{n} \geq 2$, and any fully Condorcet rule $f, G(f) \geq m-2$.

Proof: Let $\mathrm{t}$ be the selection rule for $\mathrm{f}$. Without loss of generality, we assume that $t(\{x, y, z\})=x$ and $t(\{y, z\})=y$.

Case 1. $n=4$. Let $u$ be a profile such that:

\begin{tabular}{|c|c|c|c|}
\hline 1 & 2 & 3 & 4 \\
\hline $\mathrm{x}$ & $\mathrm{y}$ & $\mathrm{z}$ & $\mathrm{z}$ \\
$\mathrm{y}$ & $\vdots$ & $\mathrm{x}$ & $\mathrm{y}$ \\
$\mathrm{z}$ & $\mathrm{x}$ & $\mathrm{y}$ & $\mathrm{x}$ \\
$\vdots$ & $\mathrm{z}$ & $\vdots$ & $\vdots$ \\
\hline
\end{tabular}

Then $\mathrm{f}(\mathrm{u})=\mathrm{t}(\{\mathrm{x}, \mathrm{y}, \mathrm{z}\})=\mathrm{x}$. If individual $\# 2$ manipulates to $\mathrm{u}^{*}$ by reporting the ordering yzx..., then $\mathrm{f}\left(\mathrm{u}^{*}\right)=\mathrm{t}(\{\mathrm{y}, \mathrm{z}\})=\mathrm{y}$ and $\# 2$ gains $\mathrm{m}-2$ ranks.

Case 2. Even $n>4$. Construct $u$ by letting $u(1), u(2), u(3)$, and $u(4)$ be as in the table above. Let $\mathrm{Q}$ be any strong ordering on $\mathrm{X}$ and set $\mathrm{p}(\mathrm{i})=\mathrm{Q}$ for any even $\mathrm{i}>4$. Let $\mathrm{R}$ be the 
inverse of $\mathrm{Q}$, and set $\mathrm{p}(\mathrm{i})=\mathrm{R}$ for every odd $\mathrm{i}>4$. Then the argument above for $\mathrm{n}=4$ can be applied without modification to establish $\mathrm{G}(\mathrm{f}) \geq \mathrm{m}-2$.

\section{Section 6. Scoring rules.}

While the previous section addressed one large class of rules, this one takes up another large class -- scoring rules, which generalize Borda's rule. Scoring rules are characterized by a sequence $\left(n_{1}, n_{2}, \ldots, n_{m-1}, n_{m}\right)$. For any ordering $r$ of $X, r[j]$ is assign the score $n_{j}$. Then, at profile $u$, each alternative $x$ in $X$ is assigned the sum of its $u(i)$ scores over all $i \in N$. $f(u)$ is then the alternative with the smallest sum. Of course, ties are possible, so a complete description of $\mathrm{f}$ requires a tie-break rule. Here we assume that $X$ is ordered ("alphabetically") and then $f(u)$ is the alphabetically earliest of the alternatives with the smallest sum. Often the sequence $\left(\mathrm{n}_{1}, \mathrm{n}_{2}, \ldots\right.$, $\left.\mathrm{n}_{\mathrm{m}-1}, \mathrm{n}_{\mathrm{m}}\right)$ is assumed to satisfy

$$
\mathrm{n}_{1} \leq \mathrm{n}_{2} \leq \ldots \leq \mathrm{n}_{\mathrm{m}-1} \leq \mathrm{n}_{\mathrm{m}}
$$

with at least one inequality strict. Such scoring rules will be called standard.

Example 6.1. (Borda rule) This rule is characterized by the sequence $(1,2, \ldots, \mathrm{m})$.

\section{Subsection 6.1. Standard rules with two values.}

We start by analyzing standard scoring rules that employ just two score values, which, without loss of generality, we take to be 0 and 1 . Consider $\mathrm{f}$ where 1 is assigned to the bottom $\mathrm{t}_{2}$ ranks and 0 is assigned to each individual's top $t_{1}$ ranks where $t_{1}+t_{2}=m$ and ties are broken alphabetically. This is a kind of approval voting, but one in which the number of approvals is the same for every individual and every profile.

Theorem 6.1. Let $\mathrm{f}$ be a standard scoring rule with two values: 
1. If $\rho(\mathrm{f})<\mathrm{m}$, then $\mathrm{G}(\mathrm{f})=\rho(\mathrm{f})-1$;

2. If $\rho(f)=m$, then $G(f)=\operatorname{Max}\left\{t_{1}-1, t_{2}-1\right\}$.

Proof: Standard rules with two scores and $\mathrm{nt}_{2} \geq \mathrm{m}$ were treated in Example 4.2 of Section 4 where it was shown that $\rho(f)=m$ but $G(f)=\operatorname{Max}\left\{t_{1}-1, t_{2}-1\right\}$. If $n_{2}<m$, some alternative is assigned 0 by everyone, so no-one's last is ever chosen; in fact, $\rho(f) \leq t_{1}$, as we now show.

Consider a profile $u$. As noted there exist alternatives to which everyone assigns 0 ; let a be the alphabetically earliest: $\mathrm{f}(\mathrm{u})=\mathrm{a}$. Alter $\mathrm{u}$ to $\mathrm{u}^{*}$ by (only) lowering a to everyone's $\mathrm{t}_{1}$ position. No scores are changed, so $f\left(u^{*}\right)=a$, and thus $\rho(f)=t_{1}$.

We now determine $\mathrm{G}(\mathrm{f})$. Construct profile $\mathrm{u}$ :

$\left.\begin{array}{|c|c|c|c|}\hline 1 & 2 & \cdots & \mathrm{n} \\ \hline \mathrm{b} & \mathrm{b} & \mathrm{b} & \mathrm{b} \\ \mathrm{x} & \mathrm{x} & \mathrm{x} & \mathrm{x} \\ \vdots & \vdots & \vdots & \vdots \\ \mathrm{a} & \mathrm{a} & \mathrm{a} & \mathrm{a} \\ \hline \mathrm{z} & \mathrm{z} & \mathrm{z} & \mathrm{z} \\ \vdots & \vdots & \vdots & \vdots\end{array}\right\} \mathrm{t}_{1}$

where $\mathrm{a}$ is in everyone's $\mathrm{t}_{1}$ position. Then $\mathrm{f}(\mathrm{u})=\mathrm{a}$. But if $\mathrm{u}^{*}$ is created by $\# 1$ interchanging a and $z$, then $f\left(u^{*}\right)=b$ and \#1 gains $t_{1}-1=\rho(f)-1$ positions. Since $f(u)$ is always in the top $t_{1}$ ranks for all individuals, $\mathrm{t}_{1}-1$ is the maximum gain and $\mathrm{G}(\mathrm{f})=\mathrm{t}_{1}-1$.

Subsection 6.2. Standard rules with three values. We next analyze scoring rules that employ three values, which, without loss of generality, we take to be $0, p$, and 1 with $0<\mathrm{p}<1$. Therefore we assume in this section that $\mathrm{m} \geq 3$. Value 1 is assigned to the bottom tier, the bottom 
$\mathrm{t}_{3}$ ranks, $\mathrm{p}$ is assigned to the middle tier, the next $\mathrm{t}_{2}$ ranks and 0 is assigned to the top tier, the top $t_{1}$, where $t_{1}+t_{2}+t_{3}=m$ and ties are broken alphabetically.

Theorem 6.2. Let $\mathrm{f}$ be a standard scoring rule with three values:

1. If $\rho(f)<m$, then $G(f)=\rho(f)-1$;

2. If $\rho(f)=m$, then $G(f)=\operatorname{Max}\left\{t_{1}+t_{2}-1, t_{2}+t_{3}-1\right\}$.

Proof: There are three cases:
A. $\mathbf{n}\left(\mathbf{t}_{2}+\mathbf{t}_{3}\right)<\mathbf{m}$;
B. $\mathbf{n t}_{\mathbf{3}} \geq \mathbf{m}$;
C. $n\left(t_{2}+t_{3}\right) \geq m$, but $n t_{3}<m$;

and we treat these in turn.

Case A. If $\mathbf{n}\left(\mathbf{t}_{\mathbf{2}}+\mathbf{t}_{\mathbf{3}}\right)<\mathbf{m}$, some alternative must be assigned 0 by everyone, so $\rho_{\mathrm{i}}(\mathrm{f}) \leq \mathrm{t}_{1}$ for all $i$ and then $\rho(f) \leq t_{1}$. Now consider a profile $u$, with $f(u)=x$. As noted, $x$ ranks no lower than position $\mathrm{t}_{1}$ for all $\mathrm{i}$. Alter $\mathrm{u}$ to $\mathrm{u}^{*}$ by (only) lowering $\mathrm{x}$ to everyone's $\mathrm{t}_{1}$ position. No scores are changed, so $f\left(u^{*}\right)=x$, and thus $\rho(f)=t_{1}$.

We now show that $G(f) \geq \rho(f)-1$. First we establish $t_{1}>1$. Suppose that $t_{1}=1$. Since $n$ $\geq 2$, we have that $n\left(t_{2}+t_{3}\right)<m$ implies $2\left(t_{2}+t_{3}\right)<m$. But $t_{1}=1$ implies $t_{2}+t_{3}=m-1$, and so $2(\mathrm{~m}-1)<\mathrm{m}$, implying $\mathrm{m}<2$, a contradiction. Therefore $\mathrm{t}_{1}>1$. 
Now that we know $\mathrm{t}_{1}>1$, construct profile $\mathrm{u}$ :

$\left.\begin{array}{|c|c|c|c|}\hline 1 & 2 & \cdots & \mathrm{n} \\ \hline \mathrm{b} & \mathrm{b} & & \mathrm{b} \\ \mathrm{x} & \mathrm{x} & \cdots & \mathrm{x} \\ \vdots & \vdots & & \vdots \\ \mathrm{a} & \mathrm{a} & & \mathrm{a}\end{array}\right\} \mathrm{t}_{1}$

where $a$ is in everyone's $t_{1}$ position. Then $f(u)=a$. But if $u^{*}$ is created by \#1 interchanging a and $\mathrm{z}, \mathrm{f}\left(\mathrm{u}^{*}\right)=\mathrm{b}$ and $\# 1$ gains $\mathrm{t}_{1}-1$ positions. Thus $\mathrm{G}(\mathrm{f}) \geq \mathrm{t}_{1}-1=\rho(\mathrm{f})-1$.

Case B. If $\mathbf{n t}_{\mathbf{3}} \geq \mathbf{m}$, then $\rho(\mathrm{f})=\mathrm{m}$. To see this, let $\mathrm{u}$ be a profile such that every alternative is in someone's last $\mathrm{t}_{3}$ ranks. Then $\mathrm{x}=\mathrm{f}(\mathrm{u})$ is in the last $\mathrm{t}_{3}$ ranks for some $\mathrm{i}$; construct $u^{*}$ by lowering $x$ to i's last rank. Then $x=f\left(u^{*}\right)=f(u)=u^{*}(i)[m]$. By anonymity, $\rho(f)=m$.

No one can manipulate from their last rank to their first. In fact, no one can manipulate from their bottom tier to their top tier, because one can't unilaterally reduce the score in one's top tier or increase the score of an alternative in one's bottom tier. So G(f) can not exceed Max $\left\{\mathrm{t}_{1}+\right.$ $\left.\mathrm{t}_{2}-1, \mathrm{t}_{2}+\mathrm{t}_{3}-1\right\}$. We will show $\mathrm{G}(\mathrm{f})=\operatorname{Max}\left\{\mathrm{t}_{1}+\mathrm{t}_{2}-1, \mathrm{t}_{2}+\mathrm{t}_{3}-1\right\}$ by showing that fallows gains of $\mathrm{t}_{1}+\mathrm{t}_{2}-1$ and $\mathrm{t}_{2}+\mathrm{t}_{3}-1$.

Part 1. We first show fallows a gain of at least $t_{1}+t_{2}-1$. 
Subcase 1. $t_{1}>1$. Consider profile $u$ :

$\left.\begin{array}{|c|c|c|c|c|}\hline 1 & 2 & \cdots & \mathrm{n}-1 & \mathrm{n} \\ \hline \mathrm{b} & \mathrm{a} & & \mathrm{a} & \mathrm{a} \\ \vdots & \vdots & \cdots & \vdots & \vdots \\ \mathrm{z} & \mathrm{b} & & \mathrm{b} & \mathrm{y}\end{array}\right\} \mathrm{t}_{1}$

where every alternative except $\mathrm{a}$ and $\mathrm{b}$ appears in someone's last $\mathrm{t}_{3}$ ranks and $\mathrm{v}$ appears there at least twice (recall $\mathrm{nt}_{3} \geq \mathrm{m}$ ). Then the sum of scores for $\mathrm{a}$ and $\mathrm{b}$ is $\mathrm{p}$ while the sum of scores for any other alternative is at least 1 . Since $a$ and $b$ are tied, the tie break gives $f(u)=a$. Now if \# 1 interchanges a and $v$, then $b$ has the smallest sum of scores and \#1 gains $t_{1}+t_{2}-1$ ranks.

Subcase 2. $\mathbf{t}_{\mathbf{1}}=1$. Suppose first that $\mathrm{n}$ is even. Consider profile $\mathrm{u}$ :

$\left.\begin{array}{|c|c|c|c|c|}\hline 1 & 2 & \cdots & \mathrm{n}-1 & \mathrm{n} \\ \hline \mathrm{b} & \mathrm{b} & \cdots & \mathrm{a} & \mathrm{a} \\ \hline \vdots & \vdots & \cdots & \vdots & \vdots \\ \mathrm{a} & \mathrm{a} & & \mathrm{b} & \mathrm{b}\end{array}\right\} \mathrm{t}_{1}$

where every alternative except $\mathrm{a}$ and $\mathrm{b}$ appear in someone's last $t_{3}$ ranks and $\mathrm{v}$ appears there at least twice. Then the sum of scores for $a$ and $b$ is $p(n / 2)$ while the sum of scores for any other alternative is more than that. Since $a$ and $b$ are tied, the tie break gives $f(u)=a$. Now if $\# 1$ 
interchanges a and $v$, then $b$ has the smallest sum of scores and $\# 1$ gains $t_{1}+t_{2}-1$ ranks.

For the case of odd $n$, note first that if $t_{2}=1$ also, then $t_{1}+t_{2}-1=1$ and we know $G(f) \geq$ 1 by Gibbard-Satterthwaite. So we may assume that $t_{2}>1$. Consider profile $u$ where all alternatives except $\mathrm{a}$ and $\mathrm{b}$ appear at least once in the bottom $\mathrm{t}_{3}$ while $\mathrm{z}$ appears at least twice in the bottom $\mathrm{t}_{3}$ :

$\left.\begin{array}{|c|c|c|c|c|c|c|}\hline 1 & \ldots & (\mathrm{n}-1) / 2 & (\mathrm{n}+1) / 2 & (\mathrm{n}+3) / 2 & \ldots & \mathrm{n} \\ \hline \mathrm{a} & \ldots & \mathrm{a} & \mathrm{z} & \mathrm{b} & \ldots & \mathrm{b} \\ \hline & & & \vdots & & & \\ \vdots & \cdots & \vdots & \mathrm{a} & \vdots & \cdots & \vdots \\ \mathrm{b} & & \mathrm{b} & \mathrm{b} & \mathrm{a} & & \mathrm{a} \\ \hline \vdots & \vdots & \vdots & \vdots & \vdots & \vdots & \mathrm{v} \\ \mathrm{z} & \mathrm{z} & & & & & \vdots\end{array}\right\} \mathrm{t}_{1}$

At $\mathrm{u}$, alternatives $\mathrm{a}$ and $\mathrm{b}$ receive scores of $\mathrm{p}(\mathrm{n}+1) / 2$; alternative $\mathrm{z}$ receives only one 0 and at least two 1's for a score of at least $2+(\mathrm{n}-3) \mathrm{p}>\mathrm{p}(\mathrm{n}+1) / 2$; all other alternatives receive no 0 's and at least one 1 for a score of at least $1+(n-1) p>p(n+1) / 2$. Thus a and $b$ tie for lowest sum and $f(u)$ $=\mathrm{a}$. But then if the nth individual interchanges $\mathrm{a}$ and $\mathrm{v}, \mathrm{b}$ is chosen and the $\mathrm{nth}$ individual gains $\mathrm{t}_{1}$ $+\mathrm{t}_{2}-1$ ranks.

Part 2. We next show $f$ allows a gain of at least $t_{2}+t_{3}-1$. If $t_{3} \leq t_{1}$, then this is settled by our proof in Part 1 that $G(f) \geq t_{1}+t_{2}-1$. So we assume that $t_{3}>t_{1}$ and in particular, that $t_{3}>1$ and $\mathrm{m}>3$.

Case 1. $t_{1}>1$. Consider profile $u$ : 


$\left.\begin{array}{|c|c|c|c|c|c|}\hline 1 & 2 & 3 & \cdots & \mathrm{n}-1 & \mathrm{n} \\ \hline \mathrm{c} & \mathrm{c} & \mathrm{a} & \cdots & \mathrm{a} & \mathrm{a} \\ \vdots & \vdots & \vdots & & \vdots & \vdots \\ \mathrm{d} & \mathrm{d} & \mathrm{b} & & \mathrm{b} & \mathrm{b} \\ \hline \mathrm{b} & \mathrm{a} & \vdots & \cdots & \vdots & \vdots \\ \vdots & \vdots & & & & \\ \hline \vdots & \vdots & \vdots & \cdots & \vdots & \vdots \\ \mathrm{a} & \mathrm{b} & & & & \end{array}\right\} \mathrm{t}_{1}$

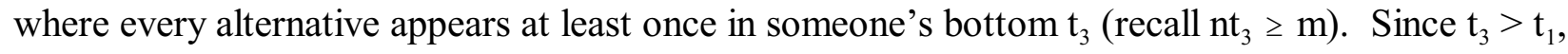
we can ensure that for each alternative in $X \backslash\{a, b\}$ there are at least as many appearances in the bottom $t_{3}$ as in the top $t_{1}$. Then $f(u)=a$, on a tie-break with $b$. But if $u^{*}$ is constructed by interchanging $\mathrm{b}$ and $\mathrm{d}$ in $\# 1$ 's ordering, $\mathrm{f}\left(\mathrm{u}^{*}\right)=\mathrm{b}$.

Case 2. $\mathbf{t}_{\mathbf{1}}=\mathbf{1}$. We first treat what happens when $\mathrm{n}$ is even. Consider $\mathrm{u}$ :

$\left.\begin{array}{|c|c|c|c|c|c|c|}\hline 12 & \multicolumn{2}{|c|}{3} & \ldots & \mathrm{n}-2 & \mathrm{n}-1 & \mathrm{n} \\ \hline \mathrm{c} & \mathrm{a} & \mathrm{b} & \cdots & \mathrm{a} & \mathrm{b} & \mathrm{b} \\ \hline \begin{array}{c}\mathrm{a} \\ \vdots\end{array} & \mathrm{b} & \vdots & & \mathrm{b} & \mathrm{a} & \vdots \\ \vdots & & & \vdots & \mathrm{a} \\ \hline \vdots & \vdots & \vdots & \cdots & \vdots & \vdots & \vdots \\ \mathrm{b} & \mathrm{c} & \mathrm{a} & & & & \end{array}\right\} \mathrm{t}_{1}$

where $\mathrm{a}$ and $\mathrm{b}$ alternate as tops for individuals $2,3, \ldots, \mathrm{n}-1$. Every alternative appears at least once in the bottom $t_{3}$. With lowest sum, $b=f(u)$. Then $\# 1$ gains $t_{2}+t_{3}-1$ ranks by interchanging a and $\mathrm{c}$.

If $\mathrm{n}$ is odd, Consider profile $\mathrm{u}$ : 


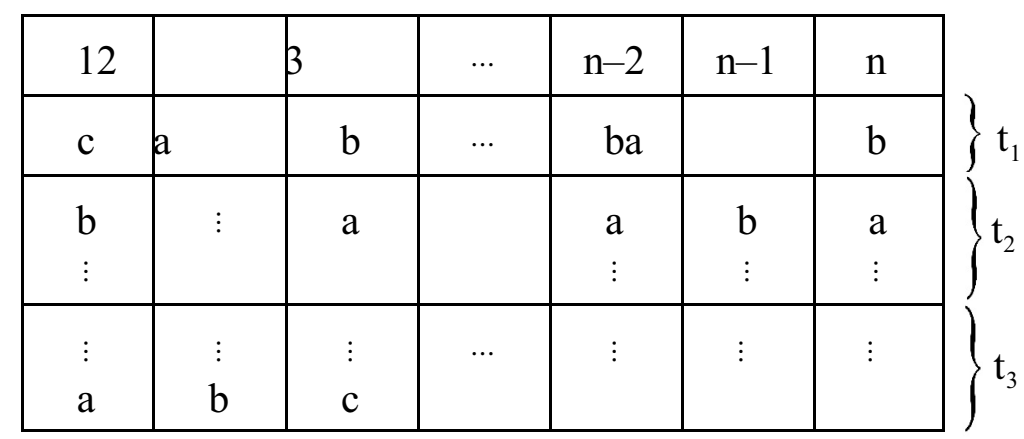

where $\mathrm{a}$ and $\mathrm{b}$ alternate as tops for individuals $2,3, \ldots, \mathrm{n}$. Every alternative appears at least once in the bottom $t_{3}$ and $\mathrm{a}$ and $\mathrm{b}$ only appear once in the bottom $\mathrm{t}_{3}$. Now $\mathrm{a}$ and $\mathrm{b}$ are tied with lowest sum and $f(u)=a$. When $\# 1$ interchanges $b$ and $c$, he gains $t_{2}+t_{3}-1$ ranks.

Case C. $n\left(t_{2}+t_{3}\right) \geq m$, and $n t_{3}<m$,

Since $n\left(t_{2}+t_{3}\right) \geq m$, there is a profile $u$ at which, for every alternative, there is an individual who has that alternative in their bottom $t_{2}+t_{3}$ ranks. In particular, someone has $\mathrm{f}(\mathrm{u})$ in their bottom $t_{2}+t_{3}$ ranks. If for any such profile $\mathrm{f}(\mathrm{u})$ is in someone's bottom $\mathrm{t}_{3}$ ranks, that profile could be modified so $\mathrm{f}(\mathrm{u})$ is in someone's $\mathrm{m}^{\text {th }}$ rank. Anonymity then implies $\rho(\mathrm{f})=\mathrm{m}$. Otherwise, for some profile $u, f(u)$ is in someone's middle $t_{2}$ ranks and that profile could be modified so $f(u)$ is at rank $t_{1}$ $+t_{2}$. Anonymity then implies $\rho(f)=t_{1}+t_{2}$. So we separate this Case into two Subcases. 
Subcase C1: $\boldsymbol{\rho}(\mathbf{f})=\mathbf{t}_{1}+\mathbf{t}_{\mathbf{2}}$. Again we first treat the case where $t_{1}>1$. Consider profile $u$ :

$\left.\begin{array}{|c|c|c|c|c|c|}\hline \mathrm{l} & 2 & 3 & \ldots & \mathrm{n}-1 & \mathrm{n} \\ \hline \mathrm{a} & \mathrm{b} & \mathrm{a} & \ldots & \mathrm{a} & \mathrm{a} \\ \vdots & \vdots & \vdots & & \vdots & \vdots \\ \mathrm{c} & \mathrm{d} & \mathrm{b} & & \mathrm{b} & \mathrm{b} \\ \hline \vdots & \vdots & \vdots & \cdots & \vdots & \vdots \\ \mathrm{b} & \mathrm{a} & & & & \\ \hline \vdots & \vdots & \vdots & \cdots & \vdots & \vdots \\ \mathrm{d} & \mathrm{c} & & & & \\ \mathrm{y}\end{array}\right\} \mathrm{t}_{1}$

where every alternative appears at least once in someone's bottom $t_{2}+t_{3}\left(\right.$ recall $\left.n\left(t_{2}+t_{3}\right) \geq m\right)$. Alternatives $a$ and $b$ have sum $p$ while all other alternatives have sum at least $p$. By the alphabetic tie-break, $\mathrm{f}(\mathrm{u})=\mathrm{a}$. If now \#2 interchanges a and $\mathrm{c}$, alternative $\mathrm{b}$ wins and $\# 2$ gains $\mathrm{t}_{1}+\mathrm{t}_{2}-1=\rho(\mathrm{f})$ - 1. Next suppose that $\mathrm{t}_{1}=1$ and $\mathrm{n}$ is even. Consider profile $\mathrm{u}$ :

$\left.\begin{array}{|c|c|c|c|c|c|}\hline 1 & 2 & 3 & \ldots & \mathrm{n}-1 & \mathrm{n} \\ \hline \mathrm{a} & \mathrm{b} & \mathrm{a} & \cdots & \mathrm{a} & \mathrm{b} \\ \hline \vdots & \vdots & \vdots & \cdots & \vdots & \vdots \\ \mathrm{b} & \mathrm{a} & \mathrm{b} & & \mathrm{b} & \mathrm{a} \\ \hline \vdots & \vdots & \vdots & \cdots & \vdots & \vdots \\ \mathrm{d} & \mathrm{c} & & & & \\ \hline\end{array}\right\} \mathrm{t}_{1}$

Alternatives $a$ and $b$ each have sum $(n / 2) p$ while all other alternatives have sum at least np. By the tie break, $\mathrm{f}(\mathrm{u})=\mathrm{a}$. If $\# 2$ interchanges a and $\mathrm{c}$, then $\mathrm{b}$ wins and $\# 2$ gains $\mathrm{t}_{1}+\mathrm{t}_{2}-1=\rho(\mathrm{f})-1$. 
If $t_{2}=1$ also, then $t_{1}+t_{2}-1=1$ and we know $G(f) \geq 1$ by Gibbard-Satterthwaite. So we assume that $t_{2}>1$. Consider the profile

$\left.\begin{array}{|c|c|c|c|c|c|}\hline 1 & 2 & 3 & \cdots & \mathrm{n}-1 & \mathrm{n} \\ \hline \mathrm{c} & \mathrm{a} & \mathrm{b} & \cdots & \mathrm{a} & \mathrm{b} \\ \mathrm{b} & & & & & \\ \vdots & \vdots & \vdots & \cdots & \vdots & \vdots \\ \mathrm{a} & \mathrm{b} & \mathrm{a} & & \mathrm{b} & \mathrm{a} \\ \hline \vdots & \vdots & \vdots & \cdots & \vdots & \vdots \\ \mathrm{d} & \mathrm{c} & \mathrm{e} & & & \\ \mathrm{y}\end{array}\right\} \mathrm{t}_{1}$

Then $a$ and $b$ have sum $p(n+1) / 2$, while all other alternatives have sum at least np. Hence, $f(u)=a$. If \#3 interchanges a and $e$, then $b$ wins and \#2 gains $t_{1}+t_{2}-1=\rho(f)-1$.

Subcase C2: $\boldsymbol{\rho}(\mathbf{f})=\mathbf{m}$. We want to show $G(f) \geq \operatorname{Max}\left\{t_{1}+t_{2}-1, t_{2}+t_{3}-1\right\}$. The argument above for the case $\rho(f)=t_{1}+t_{2}$ also suffices here to show $G(f) \geq t_{1}+t_{2}-1$. We need only show $G(f) \geq t_{2}+t_{3}-1$. Of course, if $t_{2}+t_{3}-1 \leq t_{1}+t_{2}-1$, i.e., if $t_{3} \leq t_{1}$, we are done. So we assume that $\mathrm{t}_{3}>\mathrm{t}_{1}$, and, in particular, $\mathrm{t}_{3}>1$.

We now claim that for standard scoring rules with three scores and fixed $n, m, t_{1}, t_{2}$, and $t_{3}$, such that $n\left(t_{2}+t_{3}\right) \geq m, t_{3}<m$, and $t_{3}>t_{1}$, we have (1) $\rho(f)=t_{1}+t_{2}$ if $p<1 / n$ and (2) $\rho(f)=m$ if $\mathrm{p} \geq 1 / \mathrm{n}$. To prove the first claim, suppose that $\mathrm{p}<1 / \mathrm{n}$ and $\mathrm{x}$ is in person i's bottom $\mathrm{t}_{3}$ ranks. Then $\mathrm{i}$ gives $\mathrm{x}$ a score of 1 . Since $\mathrm{nt}_{3}<\mathrm{m}$, some alternative receives only scores of 0 and $\mathrm{p}$ and so a total no greater than $\mathrm{np}$. Then having $\mathrm{x}$ win certainly requires $1 \leq \mathrm{np}$, i.e., $\mathrm{p} \geq 1 / \mathrm{n}$.

So $\mathrm{p}<1 / \mathrm{n}$ implies $\rho(\mathrm{f}) \leq \mathrm{t}_{1}+\mathrm{t}_{2}$. But since $\mathrm{n}\left(\mathrm{t}_{2}+\mathrm{t}_{3}\right) \geq \mathrm{m}$, there is a profile $\mathrm{u}$ such that every alternative is in someone's bottom $t_{2}+t_{3}$ ranks. By the previous paragraph, $f(u)$ must be in 
someone's middle $t_{2}$. Bringing that alternative down to rank $t_{1}+t_{2}$ doesn't change the outcome, so $\rho(f)=t_{1}+t_{2}$.

If $p \geq 1 / n$, consider profile $u$ :

$\left.\begin{array}{|c|c|c|c|c|c|}\hline 1 & 2 & 3 & \cdots & \mathrm{n}-1 & \mathrm{n} \\ \hline \mathrm{b} & \mathrm{a} & \mathrm{a} & \cdots & \mathrm{a} & \mathrm{a} \\ \vdots & \vdots & \vdots & & \vdots & \vdots \\ \mathrm{c} & & & & & \\ \hline \mathrm{d} & \mathrm{e} & \mathrm{f} & \cdots & & \mathrm{g} \\ \vdots & \vdots & \vdots & & \vdots & \vdots \\ \mathrm{j} & \mathrm{j} & \mathrm{j} & & \mathrm{j} & \mathrm{j} \\ \mathrm{i} & \mathrm{i} & \mathrm{i} & & \mathrm{i} & \mathrm{i} \\ \hline \vdots & \vdots & \vdots & \cdots & \vdots & \vdots \\ \mathrm{a} & & & & & \mathrm{h}\end{array}\right\} \mathrm{t}_{1}$

Here any alternative other than a that appears in the top tier appears only once (possible since $\mathrm{nt}_{1}<$ $\mathrm{m})$ and also appears once somewhere in the bottom tier (possible since $t_{3}>t_{1}$ ). The sum for a is 1 . The sum for any other alternative appearing in the top tier is at least $1+(n-2) p$. The sum for any alternative that does not appear in the top tier is at least np. Since $n p \geq 1$, alternative a at least ties for least sum and then, by the tie-break, $f(u)=a$ and $\rho(f)=m$.

So, for Subcase $\mathrm{C} 2, \rho(\mathrm{f})=\mathrm{m}$ and we have $\mathrm{p} \geq 1 / \mathrm{n}$. We must distinguish between those cases where $1 / \mathrm{n} \leq \mathrm{p}<1 /(\mathrm{n}-1)$ and those where $1 /(\mathrm{n}-1) \leq \mathrm{p}<1$.

Subcase C2A. $1 / n \leq p<1 /(n-1)$.

Consider profile u: 


$\left.\begin{array}{|c|c|c|c|c|c|}\hline 1 & 2 & 3 & \cdots & \mathrm{n}-1 & \mathrm{n} \\ \hline \mathrm{b} & \mathrm{a} & \mathrm{a} & \cdots & \mathrm{a} & \mathrm{a} \\ \vdots & \vdots & \vdots & & \vdots & \vdots \\ \mathrm{c} & & & & & \\ \hline \mathrm{d} & \mathrm{e} & \mathrm{f} & \cdots & & \mathrm{g} \\ \vdots & \vdots & \vdots & & \vdots & \vdots \\ \mathrm{j} & \mathrm{j} & \mathrm{j} & & \mathrm{j} & \mathrm{j} \\ \mathrm{d} & \mathrm{d} & & \mathrm{d} & \mathrm{d}\end{array}\right\} \mathrm{t}_{1}$

Here any alternative other than a that appears in the top tier appears only once (possible since nt ${ }_{1}<$ $\mathrm{m}$ ) and also appear once somewhere in the bottom tier (possible since $t_{3}>t_{1}$ ). The sum for a is 1 .

The sum for any other alternative appearing in the bottom tier is at least 1 . Since $\mathrm{nt}_{3}<\mathrm{m}$, at least one alternative appears only in the middle tier with sum np; let $\mathrm{d}$ be the alphabetically earliest such altenative. Since $n p>1, f(u)=a$. If $\# 1$ interchanges $b$ and $d$, then d's sum falls to $(n-1) p<1$ and $d$ is chosen, so \#1 gains $\mathrm{t}_{2}+\mathrm{t}_{3}-1$ ranks.

Subcase C2B. $1 /(n-1) \leq p<1$.

Suppose first that $t_{1}>1$. And consider profile $u$ : 


$\left.\begin{array}{|c|c|c|c|c|c|}\hline 1 & 2 & 3 & \cdots & \mathrm{n}-1 & \mathrm{n} \\ \hline \mathrm{c} & \mathrm{e} & \mathrm{a} & \cdots & \mathrm{a} & \mathrm{a} \\ \vdots & \vdots & \mathrm{b} & & \mathrm{b} & \mathrm{b} \\ \mathrm{d} & \mathrm{f} & \vdots & & \vdots & \vdots \\ \hline \mathrm{b} & \mathrm{a} & \mathrm{f} & \cdots & & \mathrm{g} \\ \vdots & \vdots & \vdots & & \vdots & \vdots \\ \mathrm{j} & \mathrm{j} & \mathrm{j} & & \mathrm{j} & \mathrm{j} \\ \mathrm{i} & \mathrm{i} & \mathrm{i} & & \mathrm{i} & \mathrm{i} \\ \hline \vdots & \vdots & \vdots & \cdots & \vdots & \vdots \\ \mathrm{a} & \mathrm{b} & & & & \mathrm{h}\end{array}\right\} \mathrm{t}_{1}$

Here any alternative other than a or b that appears in the top tier appears only once (possible since $\mathrm{nt}_{1}<\mathrm{m}$ ) and also appears at least once somewhere in the bottom tier (possible since $\mathrm{t}_{3}>\mathrm{t}_{1}$ ). The sum for $\mathrm{a}$ and $\mathrm{b}$ is $1+\mathrm{p}$. The sum for any other alternative appearing in the bottom tier is at least 1 $+(n-2)$ p. (Note $n>2$ since $1>p \geq 1 /(n-1)$.) All other alternatives appear only in the middle tier with sum np. Since $(n-1) p>1$, alternatives $a$ and $b$ are tied for low score and by the tie-break, $f(u)$ $=a$. But if $\# 1$ interchanges $d$ and $b$, the outcome changes to $b$ and $\# 1$ has gained $t_{2}+t_{3}-1$ ranks.

Consider $t_{1}=1$. Suppose $t_{2}>1$. Let $k$ be the smallest integer such that $1 / k \leq p<1$. So $(\mathrm{k}-1) \mathrm{p}<1 \leq \mathrm{kp}$. Let $\mathrm{z}=\mathrm{n}-(\mathrm{k}-1)$ and hence $\mathrm{n}-\mathrm{z}=\mathrm{k}-1$.

$\left.\begin{array}{|c|c|c|c|c|c|c|c|c|}\hline 1 & 2 & 3 & \cdots & \mathrm{z} & \mathrm{z}+1 & \cdots & \mathrm{n}-1 & \mathrm{n} \\ \hline \mathrm{c} & \mathrm{e} & \mathrm{f} & \cdots & \mathrm{r} & \mathrm{a} & \cdots & \mathrm{a} & \mathrm{a} \\ \hline \mathrm{b} & \mathrm{b} & \mathrm{b} & \cdots & \mathrm{b} & \mathrm{b} & \cdots & \mathrm{b} & \mathrm{b} \\ \vdots & \mathrm{a} & \mathrm{a} & & \mathrm{a} & \vdots & & \vdots & \vdots \\ \mathrm{j} & \vdots & \vdots & & \vdots & \mathrm{j} & & \mathrm{j} & \mathrm{j} \\ \mathrm{i} & \mathrm{i} & \mathrm{j} & & \mathrm{i} & \mathrm{i} & & \mathrm{i} & \mathrm{i} \\ \hline \vdots & \vdots & \vdots & \cdots & & & \cdots & \vdots & \vdots \\ \mathrm{a} & \mathrm{c} & \mathrm{e} & & \mathrm{f} & & & & \mathrm{h}\end{array}\right\} \mathrm{t}_{1}$


Here any alternative other than a that appears in the top tier appears only once (possible since $\mathrm{nt}_{1}<$ $m$ ) and also appears at least once somewhere in the bottom tier (possible since $t_{3}>t_{1}$ ). The sum for a is $1+(\mathrm{z}-1) \mathrm{p}$. The sum for $\mathrm{b}$ is $\mathrm{np}$. Note that $1+(\mathrm{z}-1) \mathrm{p} \leq \mathrm{np}$ because $1 \leq \mathrm{kp}$. Thus $\mathrm{f}(\mathrm{u})=\mathrm{a}$.

But if $\# 1$ interchanges $b$ and $c$, then b's sum falls to (n-1)p and (n-1)p $<1+(\mathrm{z}-1) \mathrm{p}$ since $(\mathrm{k}-1) \mathrm{p}<$ 1. Thus $b$ now is chosen and $\# 1$ has gained $t_{2}+t_{3}-1$ ranks.

\section{Subsection 6.3. m values.}

Now suppose that $\mathrm{n}_{1}<\mathrm{n}_{2}<\ldots<\mathrm{n}_{\mathrm{m}-1}<\mathrm{n}_{\mathrm{m}}$. We will treat here only the case $\mathrm{n} \geq \mathrm{m}$ (which is the analog of $\mathrm{nt}_{\mathrm{s}} \geq \mathrm{m}$ for each $\mathrm{s}$, inasmuch as each alternative can appear in each tier).

Theorem 6.3 (Scoring Rule Gain Theorem). Let $\mathrm{f}$ be a standard scoring rule with $\mathrm{n} \geq \mathrm{m}$ and $\mathrm{n}_{1}<\mathrm{n}_{2}<\ldots<\mathrm{n}_{\mathrm{m}-1}<\mathrm{n}_{\mathrm{m}}$. Then $\mathrm{G}(\mathrm{f})=\mathrm{m}-2$.

Proof: Suppose that $\mathrm{n}$ is even and greater than 2. First, no one can manipulate from their bottom tier to their top tier, because one can't unilaterally reduce the score in one's top tier or increase the score of an alternative in one's bottom tier; so $G(f) \leq m-2$. Consider profile $u$ :

\begin{tabular}{|c|c|c|c|c|c|c|c|c|c|}
\hline 1 & 2 & 3 & 4 & $\cdots$ & $\mathrm{m}$ & $\mathrm{m}+1$ & $\cdots$ & $\mathrm{n}-1$ & $\mathrm{n}$ \\
\hline $\mathrm{c}$ & $\mathrm{d}$ & $\mathrm{b}$ & $\mathrm{a}$ & $\cdots$ & $\mathrm{a}$ & $\mathrm{b}$ & $\cdots$ & $\mathrm{b}$ & $\mathrm{a}$ \\
\hline $\mathrm{b}$ & $\mathrm{a}$ & $\mathrm{a}$ & $\mathrm{b}$ & $\cdots$ & $\mathrm{b}$ & $\mathrm{a}$ & $\cdots$ & $\mathrm{a}$ & $\mathrm{b}$ \\
\hline$\vdots$ & $\vdots$ & $\vdots$ & $\vdots$ & $\vdots$ & $\vdots$ & $\vdots$ & $\cdots$ & $\vdots$ & $\vdots$ \\
\hline $\mathrm{a}$ & $\mathrm{b}$ & $\mathrm{c}$ & $\mathrm{d}$ & $\cdots$ & $\mathrm{z}$ & $\mathrm{c}$ & $\cdots$ & & \\
\hline
\end{tabular}

where $\mathrm{a}$ and $\mathrm{b}$ appear just once in the bottom row and every other alternative appears there at least once. Alternatives $a$ and $b$ have lowest score so, by the tie-break, $f(u)=a$. If $\# 1$ interchanges $b$ and 
c (leaving everything else unchanged), the tie is broken and $f\left(\mathrm{u}^{*}\right)=\mathrm{b}$ so \#1 gains $\mathrm{m}-2$ ranks.

If $\mathrm{n}$ is odd, consider profile $\mathrm{u}$ :

\begin{tabular}{|c|c|c|c|c|c|c|c|c|c|c|c|}
\hline 1 & 2 & 3 & 4 & 5 & $\ldots$ & $\mathrm{m}-1$ & $\mathrm{~m}$ & $\mathrm{~m}+1$ & $\ldots$ & $\mathrm{n}-1$ & $\mathrm{n}$ \\
\hline $\mathrm{a}$ & $\mathrm{b}$ & $\mathrm{c}$ & $\mathrm{a}$ & $\mathrm{b}$ & $\ldots$ & $\mathrm{b}$ & $\mathrm{a}$ & $\mathrm{b}$ & $\ldots$ & $\mathrm{a}$ & $\mathrm{b}$ \\
\hline $\mathrm{c}$ & $\mathrm{a}$ & $\mathrm{b}$ & $\mathrm{b}$ & $\mathrm{a}$ & $\cdots$ & $\mathrm{a}$ & $\mathrm{b}$ & $\mathrm{a}$ & $\ldots$ & $\mathrm{b}$ & $\mathrm{a}$ \\
\hline & & & $\mathrm{d}$ & $\mathrm{c}$ & & $\mathrm{c}$ & $\mathrm{d}$ & $\mathrm{c}$ & & $\mathrm{d}$ & $\mathrm{c}$ \\
\hline$\vdots$ & $\vdots$ & $\vdots$ & $\vdots$ & $\vdots$ & $\vdots$ & & $\vdots$ & $\vdots$ & $\ldots$ & $\vdots$ & $\vdots$ \\
\hline $\mathrm{b}$ & $\mathrm{c}$ & $\mathrm{a}$ & $\mathrm{c}$ & $\mathrm{d}$ & $\cdots$ & $\mathrm{y}$ & $\mathrm{z}$ & $\mathrm{d}$ & $\cdots$ & & \\
\hline
\end{tabular}

where $\mathrm{a}$ and $\mathrm{b}$ appear just once in the bottom row and every other alternative appears there at least once. Alternatives $a$ and $b$ are tied for lowest sum, so $f(u)=a$. If $\# 3$ now interchanges $b$ and $c$ (leaving everything else unchanged), $\mathrm{f}\left(\mathrm{u}^{*}\right)=\mathrm{b}$ and \#3 gains $\mathrm{m}-2$ ranks.

\section{Section 7. Tops-only and vector rules.}

In this section we treat a large class of rules that generalize tops-only rules. We say that $\mathrm{f}$ is a tops-only rule if for every two profiles $\mathrm{u}$ and $\mathrm{v}, \mathrm{u}(1)[1], \mathrm{u}(2)[1], \ldots, \mathrm{u}(\mathrm{n})[1])=(\mathrm{v}(1)[1], \mathrm{v}(2)[1]$, $\ldots, v(n)[1])$ implies $f(u)=f(v)$. We may not have $f(u) \in\left\{u(1)\left[t_{1}\right], u(2)\left[t_{2}\right], \ldots, u(n)\left[t_{n}\right]\right\}$ :

Example 7.1. Fix two alternatives $x$ and $a$ in $X . f(u)=u(1)[1]$ unless $u(1)[1]=x$, in which case $\mathrm{f}(\mathrm{u})=\mathrm{a}$.

Theorem 7.1 (Tops-only Gain). For any non-dictatorial tops-only rule f with $\mid$ Range(f) $\mid>$ $2, \mathrm{G}(\mathrm{f}) \geq \mathrm{m}-2$.

Proof: Since f is non-dictatorial and $|\operatorname{Range}(\mathrm{f})|>2$, Gibbard-Satterthwaite tells us $\mathrm{f}$ is manipulable. Suppose $f$ is manipulable by $i$ at profile $u$ to $i$-variant profile $v$. Then $f(u)$ is not $u(i)[1]$ 
or $\mathrm{i}$ has no incentive to manipulate. If necessary, alter $\mathrm{u}$ by taking $\mathrm{f}(\mathrm{u})$ to the bottom of $\mathrm{u}(\mathrm{i})$. If $\mathrm{f}(\mathrm{v})$ is $u(i)[1]$ or $u(i)[2]$, the manipulation yields a gain of at least $m-2$. Otherwise, alter $u$ to put $f(v)$ in the second rank. Then manipulating to $\mathrm{v}$ yields a gain of $\mathrm{m}-2$.

Both $m-1$ and $m-2$ are possible gain values for non-dictatorial tops-only rules $f$ with $\mid$ Range(f) $\mid>2$ :

Example 7.2. Let $\mathrm{f}$ select the alphabetically earliest alternative that is no-one's top. Suppose that at $\mathrm{u}, \# 1$ has a at the top and $\mathrm{b}$ at the bottom while everyone else has $\mathrm{c}$ on top. Then $\mathrm{f}(\mathrm{u})=\mathrm{b}$. But if $\# 1$ reports a preference with $\mathrm{c}$ on top, then $\mathrm{b}$ is chosen and \#1 gains $\mathrm{m}-1$ ranks.

Example 7.3. Let $\mathrm{f}$ select the alphabetically earliest top. Suppose that at $\mathrm{u}, \# 1$ has $\mathrm{c}$ at the top, a second, and $b$ at the bottom while everyone else has $b$ on top. Then $f(u)=b$. But if \#1 reports a preference with a on top, then a is chosen and \#1 gains $m-2$ ranks. Since no-one can manipulate to their top. $G(f)=m-2$.

We can generalize: A rule $\mathrm{f}$ is a vector rule if there is a vector $\left(t_{1}, t_{2}, \ldots, t_{n}\right)$ of integers each belonging to $\{1,2, \ldots, m\}$ such that for every two profiles $u$ and $v,\left(u(1)\left[t_{1}\right], u(2)\left[t_{2}\right], \ldots, u(n)\left[t_{n}\right]\right)=$ $\left(v(1)\left[t_{1}\right], v(2)\left[t_{2}\right], \ldots, v(n)\left[t_{n}\right]\right)$ implies $f(u)=f(v)$. For such a vector rule, we may abuse notation a little and express $\mathrm{f}(\mathrm{u})$ as $\mathrm{f}\left(\mathrm{u}(1)\left[\mathrm{t}_{1}\right], \mathrm{u}(2)\left[\mathrm{t}_{2}\right], \ldots, \mathrm{u}(\mathrm{n})\left[\mathrm{t}_{\mathrm{n}}\right]\right)$ An example of a vector rule that is not tops-only is inverse plurality, Example 2.3.

In the following theorem, given without proof, there is no restriction on the parity of $n$.

Theorem 7.2 (Vector Rule Gain Theorem). For $\mathrm{m}>\mathrm{n}$, Let $\mathrm{f}$ be any non-dictatorial vector rule with $\mid$ Range(f) $\mid>3$ :

(1) If $\rho(f)=m$, then $G(f) \geq m-2$; 
(2) If $1<\rho($ f $)<$ m, then $G(f) \geq \rho($ f $)-1$.

We conjecture that the Vector Rule Gain Theorem also holds for $\mathrm{m} \leq \mathrm{n}$.

\section{Section 8. Final remarks.}

For the benchmark case $\rho(\mathrm{f})<\mathrm{m}$, all our examples and analyses so far confirm Gain Conjecture $\# 1$ : $G(f) \geq \rho(f)-1$. But for $\rho(f)=m, G(f)$ can be as small as $m / 2-1$, as illustrated by three kinds of rules in Section 4. All our examples confirm Gain Conjecture \#2: $G(f) \geq m / 2-1$. But for most situations with $\rho(f)=m, G(f)$ is either $m-1$ or $m-2$. Obviously, we need something beyond $\rho(f)$ to sort out the variety of outcomes when $\rho(f)=m$.

For all the classes of rules we have considered and, assuming the Gain Conjectures, for all non-dictatorial rules with at least three alternatives in the range, small maximal gains can only be achieved if some one individual has a great deal of power in determining the values of $\mathrm{f}$. More carefully, if $\mathrm{G}(\mathrm{f})<\mathrm{m} / 2-1$, then $\rho(\mathrm{f})<\mathrm{m} / 2$ and some individual $\mathrm{i}$ can precipitate the chosen alternative to be from some initial segment of their ordering, $u(i)[1: \rho(f)]$. And that can be true for only one individual as, for any $\mathrm{j} \neq \mathrm{i}$, there is a $\mathrm{u}$ with $\mathrm{u}(\mathrm{j})[1: \rho(\mathrm{f})]$ disjoint from $\mathrm{u}(\mathrm{i})[1: \rho(\mathrm{f})]$.

\section{References}

Aleskerov, F. and E. Kurbanov (1990) Degree of manipulability of social choice procedures. In:

Current Trends in Economics. Eds: Alkan, A., Aliprantis, C. D. and Yannelis, N. C. (Springer) 13-27.

Baharad, E. and S. Nitzan. (2005) The inverse plurality rule - An axiomatization. Social Choice and Welfare 25: 173-178.

Barberà, S. (1983) Strategy-proofness and pivotal voters: A direct proof of the Gibbard- 
Satterthwaite theorem. International Economic Review 24: 413-418.

Benoit, J.-P. (2000) The Gibbard-Satterthwaite theorem: A simple proof. Economics Letters 69:319-322.

Campbell, D. E. and J. S. Kelly (2007) Losses Resulting from Manipulation of Social Choice Rules.

Chamberlain, J. (1985) Investigation into the relative manipulability of four voting systems. Behavioral Science 30: 195-203.

Ehlers, L., H. Peters, and T. Storcken (2004) Threshold strategy-proofness: On manipulability in large voting problems. Games and Economic Behavior 49: 103-116.

Favardin, P., D. Lepelley, and J. Serias (2002) Borda rule, Copeland method, and strategic manipulation. Review of Economic Design 7: 213-228.

Fristrup, P. and H. Keiding (1998) Minimal manipulability and interjacancy for two-person social choice functions. Social Choice and Welfare 15: 455-467.

Gibbard, A. (1973) Manipulation of voting schemes: A general result. Econometrica 41: $587-601$.

Kelly, J. S. (1988) Minimal manipulability and local strategy-proofness. Social Choice and Welfare 5: 81-85.

Kelly, J. S. (1993) Almost all social choice rules are highly manipulable, but a few aren't. Social Choice and Welfare 10: 161-175.

Kim, K. H. and F. W. Roush (1996) Statistical manipulability of social choice functions. Group Decision and Negotiation 5: 263-282. 
Lepelley, D. and B. Mbih (1987) The proportion of coalitionally unstable situations under plurality rule. Economic Letters 24: 311-315.

Lepelley, D. and B. Mbih (1994) The vulnerability of four social choice functions to coalitional manipulation of preferences. Social Choice and Welfare 11:253-265.

Mas-Colell, A., M. D. Whinston and J. R. Green (1995) Microeconomic Theory (Oxford University Press).

Maus, S., H. Peters, and T. Storcken (2005a) Minimal manipulability: Anonymity and unanimity.

Maus, S., H. Peters, and T. Storcken (2005b) Minimal manipulability: Unanimity and nondictatorship.

Maus, S., H. Peters, and T. Storcken (2005c) Minimal manipulability: Anonymity and surjectivity.

Maus, S., H. Peters, and T. Storcken (2005d) Anonymous voting and minimal manipulability.

Nitzan, S. (1985) The vulnerability of point-voting schemes to preference variation and strategic manipulation. Public Choice 47: 349-370.

Nurmi, H. (1987) Comparing Voting Systems (Reidel).

Pattanaik, P. K. (1976) Counter-threats and strategic manipulation under voting schemes. Review of Economic Studies 43:11-18.

Pattanaik, P. K. (1976) Threats, counter-threats and strategic voting. Econometrica 44:91-103.

Pattanaik, P. K. (1978) Strategy and Group Choice (North Holland).

Peleg, B., A Note on Manipulability of Large Voting Schemes. Theory and Decision 11: 401412.

Pritchard, G. and A. Slinko (2006) On the average minimum size of a winning coalition. Social 
Choice and Welfare 27: 263-277.

Saari, D. (1990) Susceptibility to manipulation. Public Choice 64: 21-41.

Satterthwaite, M. A. (1975). Strategy-proofness and Arrow's conditions: Existence and correspondence theorems for voting procedures and social welfare functions. Journal of Economic Theory 10: 187-217.

Schummer, J. (2004) Almost-dominant strategy implementation: Exchange economies. Games and Economic Behavior 48: 154-170.

Smith, D. A. (1999) Manipulability measures of common social choice functions. Social Choice and Welfare 16: 639-661.

Sonnenschein, H. (1998) “The Economics of Incentives: An Introductory Account,” in: Frontiers of Research in Economic Theory: The Nancy L. Schwartz Memorial Lectures, 1983-1997 edited by D. P. Jacobs, E. Kalai, and M. I. Kamien (Cambridge University Press) 3-15. 